\title{
Development of an optimized method for the detection of airborne viruses with real-time PCR analysis
}

Panos G Ziros, Petros A Kokkinos, Euaggelia Legaki and Apostolos Vantarakis ${ }^{*}$

\begin{abstract}
Background: Airborne viruses remain one of the major public health issues worldwide. Detection and quantification of airborne viruses is essential in order to provide information regarding public health risk assessment.

Findings: In this study, an optimized new, simple, low cost method for sampling of airborne viruses using Low Melting Agarose (LMA) plates and a conventional microbial air sampling device has been developed. The use of LMA plates permits the direct nucleic acids extraction of the captured viruses without the need of any preliminary elution step. Molecular detection and quantification of airborne viruses is performed using real-time quantitative (RT-)PCR (Q(RT-)PCR) technique. The method has been tested using Adenoviruses (AdVs) and Noroviruses (NoVs) GII, as representative DNA and RNA viruses, respectively. Moreover, the method has been tested successfully in outdoor experiments, by detecting and quantifying human adenoviruses (HAdVs) in the airborne environment of a wastewater treatment plant.
\end{abstract}

Conclusions: The great advantage of LMA is that nucleic acids extraction is performed directly on the LMA plates, while the eluted nucleic acids are totally free of inhibitory substances. Coupled with QPCR the whole procedure can be completed in less than three (3) hours.

Keywords: airborne viruses, air sampling, air pollution, human adenovirus, norovirus, and wastewater treatment plant

\section{Background}

Viruses are pathogenic to humans and animals. There is a growing concern regarding exposure to bioaerosols since they represent major health and economic risks to human and animal populations. Exposure to airborne viruses in different environments is responsible for various health problems and disorders worldwide [1]. Moreover, there is an increased concern of using highly pathogenic airborne microorganisms, as bioterrorism agents. Aerosolization of viral pathogens occurs in processes such as spray irrigation of wastewater and operation of sewage treatment plants, but also from humans and animals as a result of coughing, sneezing, breathing, especially in indoor air environments [1-3]. The question

\footnotetext{
* Correspondence: avantar@med.upatras.gr

Environmental Microbiology Unit, Department of Public Health, School of Medicine, University of Patras, Rion, GR 26504, Greece
}

of airborne transmission is especially important for the waste treatment plant workers and for healthcare workers where patients tend to congregate during for example influenza season [4]. Many highly pathogenic viruses, such as SARS coronavirus (SARS-CoV), which causes severe acute respiratory syndrome, a highly infectious disease with a significant mortality, have the potential of being converted from droplet to airborne transmission and for that reason health care workers are particularly vulnerable [5]. Airborne spread of the SARS epidemic has been suggested for the transmission of the disease in Hong Kong in 2003 and several epidemiological studies have proposed an airborne transmission for various pathogenic viruses [6-10].

To control and prevent exposure to airborne viruses, efficient monitoring through accurate sampling is fundamental. Many types of samplers have been used over the
C Biomed Central

(c) 2011 Ziros et al; licensee BioMed Central Ltd. This is an Open Access article distributed under the terms of the Creative Commons Attribution License (http://creativecommons.org/licenses/by/2.0), which permits unrestricted use, distribution, and reproduction in any medium, provided the original work is properly cited. 
years, including liquid impingers, solid impactors, filters, electrostatic precipitators, and many others [8]. In this study, we used low melting agarose (LMA) as a capture medium instead of agar based media, since preliminary spiking experiments using Tryptic Soy Agar (TSA) resulted in very pure recovery efficiencies $(5-10 \%$ recoveries, data not shown), due to inhibition of the final Q (RT-)PCRs. Agar itself has been reported to cause inhibition of the PCR assay [11]. On the other hand, the use of LMA has been shown to improve the PCR amplification from templates which were naturally contaminated by various PCR inhibitors [12].

\section{Methods}

\section{Preparation of LMA plates and air sampling}

Airborne viruses were captured on LMA plates $(0.5 \%$ LMA) in acidic conditions (0.05 M Glycine, pH 3.5). LMA plates were prepared by dissolving 0.5 gr of Low Melting Agarose (Invitrogen) in $100 \mathrm{ml}$ of Glycine buffer, $\mathrm{pH}$ 3.5. The LMA solution was autoclaved for $20 \mathrm{~min}$ and after being cooled down to $40^{\circ} \mathrm{C}$ in a water bath, $(2 \mathrm{ml})$ was transferred to $60 \mathrm{~mm}$ Petri dishes. The LMA plates were left at room temperature in order to solidify and stored at $4{ }^{\circ} \mathrm{C}$ until used. Air was sampled at a programmable flow rate using the Surface Air System (SAS International $\mathrm{Pbi}$, Italy), an impactor sampler with contact agar plates. These plates were filled with $2 \mathrm{ml}$ of LMA instead of agar, as described above.

\section{Spiking experiments}

Spiking experiments were performed using Human Adenovirus 35 (HAdV-35) and Human Norovirus GII (NoV) (kindly donated by Annika Allard, Umeå University, Sweden). Virus titres of approximately $10^{5}$ copies $/ \mathrm{ml}$ for HAdV, and $10^{6}$ copies $/ \mathrm{ml}$ for NoV were used. In order to test the efficiency of virus recovery from LMA plates, three (3) different sets of samples were spiked with serial dilutions of $100 \mu \mathrm{l}$ viral suspensions in PBS and spread on the surface of the plates, using a $2 \mu \mathrm{l}$ eppendorf pipette. LMA plates were seeded with (i) HAdV containing
$1 \times 10^{4}$ GC (ii) HAdV containing $1 \times 10^{3}$ GC (iii) HAdV containing $1 \times 10^{2} \mathrm{GC}$ (Table 1 ). Before NA extraction, all samples were placed on SAS air sampler and air sampling was performed under sterile conditions for $20 \mathrm{~min}$ (at constant flow rate of 150 lt per minute) in a level two cell culture laminar flow. NA extraction was performed directly from the LMA plates and virus recovery was estimated with QPCR for HAdV. In a second set of spiking experiments, an RNA virus was tested. To this end, NoV GII was used in three different sets of samples spiked with $1 \times 10^{4}, 1 \times 10^{3}$ and $1 \times 10^{2} \mathrm{GC}$ of NoV, as shown in Table 2. NA extraction was performed directly from the LMA plates and virus recovery was estimated with QRT-PCR for NoV GII.

\section{Nucleic acid extraction}

Nucleic acid (NA) extraction from LMA plates was performed using the NucliSENS Magnetic extraction Reagents (bioMerieux, France) according to kit instructions, with the following minor modifications. In detail, $4 \mathrm{ml}$ of NucliSENS lysis buffer were added to each LMA plate. Upon addition of lysis buffer LMA was easily dissolved. Then the lysate was transferred to $15 \mathrm{ml}$ falcon tube, briefly vortexed and incubated for $10 \mathrm{~min}$ at $55^{\circ} \mathrm{C}$ in a water bath. Afterwards, $50 \mu \mathrm{l}$ of well-mixed magnetic silica were added to the lysate and the instructions of the manufacturer were followed until the final step of NA elution. NAs were finally extracted in $50 \mu \mathrm{l}$ of elution buffer, and extracts were stored at $-20^{\circ} \mathrm{C}$ until analyzed by QPCR. It is worthy of note that any commercial or homemade nucleic acid extraction reagent using a lysis buffer based on GuSCN can be used.

\section{Real time Q(RT-)PCR analyses}

The quantitative real-time PCR (QPCR) for human Adenovirus based on the method described by Hernroth and colleagues [13], was performed in a final volume of $25 \mu \mathrm{l}$, using the TaqMan Universal PCR master mix (Invitrogen). The sensitivity of this QPCR HAdV assay has been estimated to be of 1-10 genome copies $[13,14]$. The

Table 1 Recovery values of HAdV 35 seeded in LMA plates

\begin{tabular}{|c|c|c|c|c|}
\hline Sample ID & HAdV added GC/plate & HAdV recovered GC/plate & $\begin{array}{l}\text { Recovery } \\
\text { (\%) }\end{array}$ & $\begin{array}{c}\text { Mean recovery } \\
(\%)\end{array}$ \\
\hline exp1 & $1 \times 10^{4}$ & $0,47 \times 10^{4}$ & 47 & 81 \\
\hline $\exp 2$ & $1 \times 10^{4}$ & $1,01 \times 10^{4}$ & 101 & \\
\hline $\exp 3$ & $1 \times 10^{4}$ & $0,95 \times 10^{4}$ & 95 & \\
\hline exp4 & $1 \times 10^{3}$ & $0,59 \times 10^{3}$ & 59 & 60,3 \\
\hline $\exp 5$ & $1 \times 10^{3}$ & $0,59 \times 10^{3}$ & 59 & \\
\hline exp6 & $1 \times 10^{3}$ & $0,6 \times 10^{3}$ & 63 & \\
\hline exp7 & $1 \times 10^{2}$ & $0,42 \times 10^{2}$ & 42 & 33,7 \\
\hline $\exp 8$ & $1 \times 10^{2}$ & $0,26 \times 10^{2}$ & 26 & \\
\hline $\exp 9$ & $1 \times 10^{2}$ & $0,33 \times 10^{2}$ & 33 & \\
\hline
\end{tabular}


Table 2 Recovery values of NoV GIl seeded in LMA plates

\begin{tabular}{|c|c|c|c|c|}
\hline Sample ID & NoV GIl added GC/plate & NoV GII recovered GC/plate & $\begin{array}{c}\text { Recovery } \\
(\%)\end{array}$ & $\begin{array}{c}\text { Mean recovery } \\
(\%)\end{array}$ \\
\hline exp1 & $1 \times 10^{4}$ & $0,94 \times 10^{4}$ & 93 & 90,3 \\
\hline $\operatorname{exp2}$ & $1 \times 10^{4}$ & $1,06 \times 10^{4}$ & 106 & \\
\hline $\operatorname{exp3}$ & $1 \times 10^{4}$ & $0,72 \times 10^{4}$ & 72 & \\
\hline $\exp 4$ & $1 \times 10^{3}$ & $0,91 \times 10^{3}$ & 91 & 93,3 \\
\hline $\exp 5$ & $1 \times 10^{3}$ & $1,07 \times 10^{3}$ & 107 & \\
\hline exp6 & $1 \times 10^{3}$ & $0,82 \times 10^{3}$ & 82 & \\
\hline exp7 & $1 \times 10^{2}$ & $0,93 \times 10^{2}$ & 93 & 63,3 \\
\hline $\exp 8$ & $1 \times 10^{2}$ & $0,68 \times 10^{2}$ & 68 & \\
\hline $\exp 9$ & $1 \times 10^{2}$ & $0,29 \times 10^{2}$ & 29 & \\
\hline
\end{tabular}

following oligonucleotide primers and conditions were used. Forward primer: AdF (5'- CWT ACA TGC ACA TCK CSG G-3'), at a final concentration of $0.9 \mu \mathrm{M}$, Reverse primer: AdR (5'- CRC GGG CRA AYT GCA CCA G-3'), at a final concentration of $0.9 \mu \mathrm{M}$, Adenovirus TaqMan Probe: AdP1 (5'- FAM- CCG GGC TCA GGT ACT CCG AGGCGT CCT-BHQ-3'), at a final concentration of $0.225 \mu \mathrm{M}$. The temperature-time program was as follows: $2 \mathrm{~min}$ at $50^{\circ} \mathrm{C}, 10 \mathrm{~min}$ at $95^{\circ} \mathrm{C}$ as a hot start, and 45 cycles of $15 \mathrm{~s}$ at $95^{\circ} \mathrm{C}$ for denaturation, 1 min at $60^{\circ} \mathrm{C}$ for denaturation, annealing-extension. Standard curves used in the QPCR were generated by using serial dilutions of purified viral genomic DNA from adenovirus 35 (HAdV-35) viral stocks.

The quantitative real-time RT-PCR (QRT-PCR) for human Norovirus GII (detection limit < 10 copies per reaction) based on a method described previously [15], was performed in a final volume of $20 \mu \mathrm{l}$, using the RNA UltraSense $^{\mathrm{TM}}$ One-Step Quantitative RT-PCR System (Invitrogen). The following primers and conditions were used. Forward primer: QNIF2 (5'- ATG TTC AGR TGG ATG AGR TTC TCW GA -3'), Reverse primer: COG2R (5' - TCG ACG CCA TCT TCA TTC ACA -3'), Norovirus GG II Probe: QNIFS (5'- FAM- AGC ACG TGG GAG GGC GAT CG -BHQ1-3'). The temperature-time program was as follows: $15 \mathrm{~min}$ at $50^{\circ} \mathrm{C}$ for the $\mathrm{RT}$ reaction, $10 \mathrm{~min}$ at $95^{\circ} \mathrm{C}$ as a hot start, and 45 cycles of $15 \mathrm{~s}$ at $95^{\circ} \mathrm{C}$ for denaturation, $1 \mathrm{~min}$ at $60^{\circ} \mathrm{C}$ for denaturation, annealing-extension. Standard curves used in the QRTPCR were generated by using serial dilutions of purified viral genomic RNA from NoV GII viral stocks.

Internal amplification controls (IAC) for human Adenovirus (YORKBIO Cat\# IAC-HADV, UK) and Norovirus GII (YORKBIO Cat\# IAC-NVGII, UK) were used in order to test the eluted nucleic acids for the presence of inhibitory substances. The following TaqMan probe was used, IAC probe: IACP (5'-VIC-CCA TAC ACA TAG GTC AGG -MGBNFQ-3'), while the primers and conditions were the same to those for HAdV and NoVGII QPCRs, respectively.
Standard precautions were applied in all Q(RT-)PCR assays, such as use of separate work areas and pipettes for pre- and post-amplification steps.

\section{Outdoor experiments}

In order to test the LMA method of air sampling under field conditions, air sampling experiments were performed in an urban area of the city of Patras, located in southwestern Greece, and in the sewage treatment plant of Patras' University (SWPT). Samplings at the SWPT were performed during a two months period of summer 2010 at the plant's Aerobic Wastewater Mechanical Aeration Treatment System. Each air sampling was performed for 20 min, which corresponds to 3000 lt of air at a distance of $1 \mathrm{~m}$ from the sewage tank, except for two samples which where collected outside the SWTP facilities, at a distance of approximately $50 \mathrm{~m}$ from the sewage tank (Table 3). This SWTP operates periodically every 3 hours for $30 \mathrm{~min}$. Samplings were performed under both conditions, during operation or immediately after the end of an operation cycle (Table 3). After sampling, the LMA plates were processed on the same day for NA extraction. NA extracts $(50 \mu \mathrm{l})$ were stored at $-20 \mathrm{C}$ until analyzed.

QPCR for HAdV detection and quantification were performed under the same experimental conditions described previously, except for the construction of the standard curve which was generated by using serial dilutions (range 1 to $10^{7}$ ) of known amounts of a linearized plasmid containing the entire hexon region of HAdV 41 (kindly donated by Annika Allard, Umeå University, Sweden) (Figure 1).

\section{Results}

\section{Efficiency of viral recovery from LMA plates}

HAdV recovery from LMA plates was estimated with QPCR. Mean values of three independent experiments for the determination of viral recovery were $81 \%$ (for the samples spiked with $1 \times 10^{4} \mathrm{GC}$ ), $60.3 \%$ (for the samples spiked with $1 \times 10^{4} \mathrm{GC}$ ), and $33.7 \%$ (for the samples spiked with $1 \times 10^{2} \mathrm{GC}$ ) (Table 1 ). 
Table 3 Detection and quantification of Human Adenovirus in the air of SWTP

\begin{tabular}{cccc}
\hline Sample ID & SWTP operation & Adenovirus load per $\mathbf{3 0 0 0}$ It of air & Distance from the tank (m) \\
\hline A3559 & yes & 384 & 1 \\
A3560 & yes & 116 & 1 \\
A3561 & no & 39 & 1 \\
B3568 & no & 6,5 & 1 \\
B3569 & no & ND & 1 \\
A3602 & yes & 75 & 1 \\
A3603 & yes & 79 & 1 \\
A3604 & no & 6,7 & 1 \\
C3622 & no & 69 & 1 \\
C3624 & yes & 1017 & 1 \\
C3623 & no & 83 & 1 \\
H3761 & yes & 34 & 50 \\
H3762 & no & ND & 50 \\
\hline
\end{tabular}

Detection and quantification of Human Adenovirus in the air of a SWTP using the LMA method and QPCR. Sample IDs with the same initiating letter were sampled during the same day. (ND: Not detected)

A)

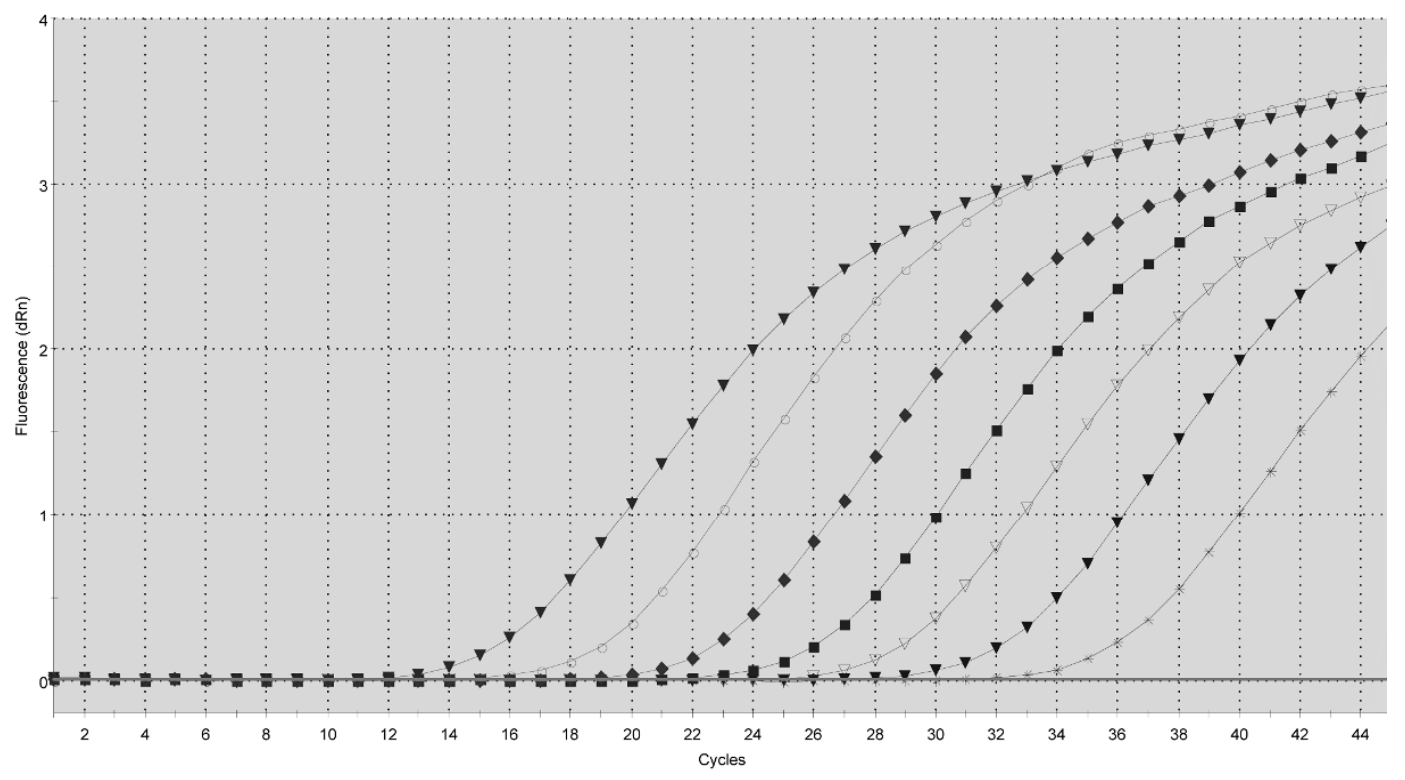

B)

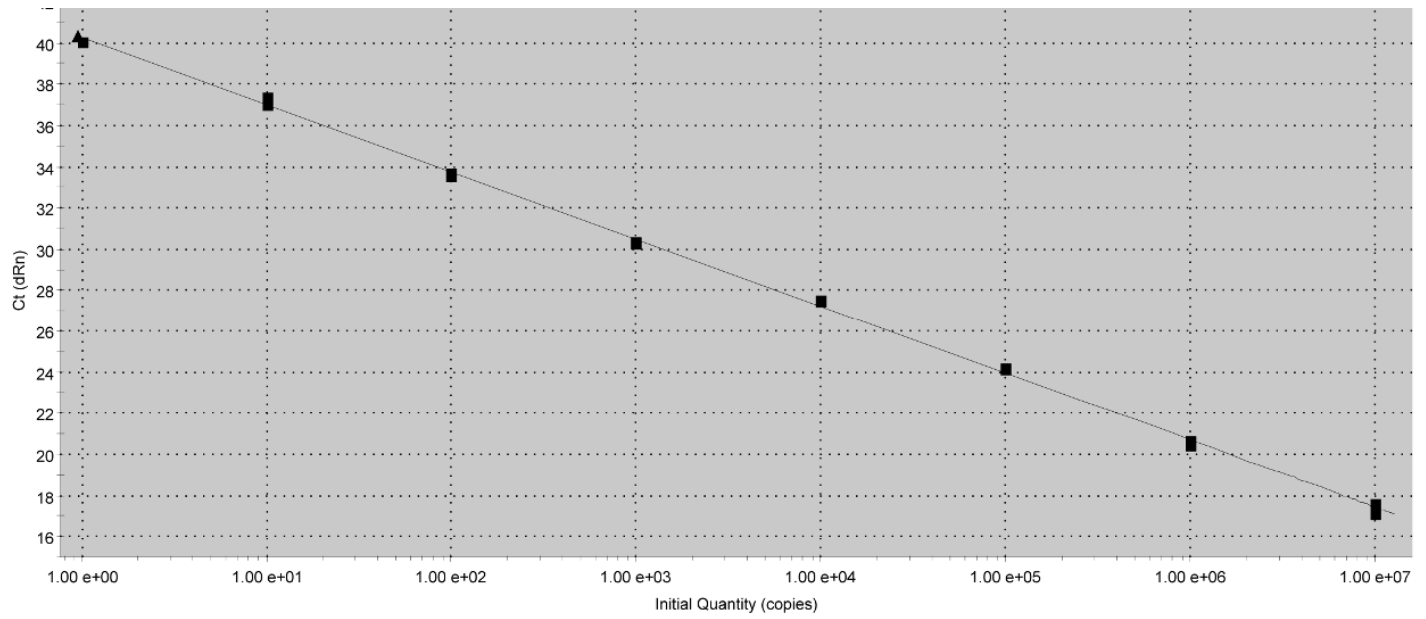

Figure 1 Real-time -PCR quantification of HAdV 41 standard plasmid. A) Amplification plots of fluorescence intensities ( $\triangle R n)$ versus the PCR cycle numbers are displayed for serial 10-fold dilutions of standard plasmids ( $1 \times 10^{7}$ to 1 copy per reaction). B) Standard curve generated using a 10 -fold dilution series $\left(1 \times 10^{7}\right.$ to 1 copies per reaction) of HAdV 41 standard plasmid. Slope $=-3.262$, Y-intercept $=40.27, R^{2}=0.999$. 
NoV GII recovery from LMA plates was estimated with QRT-PCR. The mean viral recovery values of three independent experiments were $90.3 \%$ (for the samples spiked with $1 \times 10^{4} \mathrm{GC}$ ), $93.3 \%$ (for the samples spiked with $1 \times 10^{4} \mathrm{GC}$ ), and $63.3 \%$ (for the samples spiked with $1 \times 10^{2} \mathrm{GC}$ ) (Table 2).

The NA extracts from the field experiments were tested for inhibition against control samples of pure NA elution buffer, with the use of previously described IACs. No statistically significant difference was observed between the LMA samples and the control samples. Regarding HAdV, the mean Ct value for LMA samples was 34.4 (SD 0.44), while the Control Ct was 34.4 (SD 0.39 ). For the NoVGII analyses, the mean $\mathrm{Ct}$ values for the LMA samples was 30.53 (SD 0.27), while the Control Ct value was 30.29 (SD 0.38).

\section{Detection of viruses in outdoor experiments}

As it is shown in Table 3, HAdV were detected in eleven (11) out of thirteen (13) samples collected at the SWTP. At the Aerobic Wastewater Mechanical Aeration Treatment System the results indicated a considerable airborne viral pollution, with HAdV detected in $84.6 \%$ of the tested samples. Interestingly, $100 \%$ of the samples were found to be positive when the SWTP was in operation. HAdV were not detected in anyone of the samples (six samples) originating from the urban area of the city. QRT-PCR for Norovirus GII detection were also performed in the same samples. No positive $\mathrm{NoV}$ GII samples were detected, neither to the urban area, nor to the wastewater treatment plant.

\section{Discussion and conclusions}

The results of the present study showed that Low Melting Agarose (LMA) can be efficiently used as a capturing medium of airborne viruses in solid impactor air samplers. Usually, sampling with this type of air samplers is performed using agar based media [8]. The drawback of agar plates is that viruses have to be eluted from the agar plates before the subsequent nucleic acid extraction step, which results in viral losses. Moreover, inhibitory substances presented in the agar media tend to remain during the subsequent NA isolation and finally inhibit the $\mathrm{Q}$ (RT-)PCR reactions, thus considerably reducing the detection limit of airborne viruses. In contrary, the great advantage of LMA is that NA extraction is performed directly on the LMA plates, while the eluted NA is totally free of inhibitory substances. Coupled with QPCR the whole procedure can be completed in less than three (3) hours.

In accordance to the findings of others studies, which support that the wastewater treatment plants are sources of considerable airborne contamination, which may pollute the environment and constitute an important biological hazard for workers $[2,16,17]$, the present study revealed a significantly high level of viral contamination during the operation of the studied SWTP.

We intend to apply this optimized method for the detection of airborne viruses in indoor and outdoor environments.

\section{List of abbreviations}

HAdV: human adenovirus; NoV: norovirus; LMA: low melting agarose; SWTP: sewage treatment plant; QPCR: quantitative real time PCR; GC: genome copies; NA: nucleic acids.

\section{Authors' contributions}

PZ was responsible for setting up the study, performed the samplings at the SWTP, and participated in the molecular analyses and in the writing of the manuscript. PK performed the samplings at the urban areas, and participated in the writing and revision of the manuscript; EL performed the nucleic acid extractions, while AV was responsible for coordinating the study, and drafted the manuscript. All authors read and approved the final manuscript.

\section{Competing interests}

The authors declare that they have no competing interests.

Received: 28 June 2011 Accepted: 27 July 2011 Published: 27 July 2011

\section{References}

1. Douwes J, Thorne P, Pearce N, Heederik D: Bioaerosol health effects and exposure assessment: progress and prospects. Ann Occup Hyg 2003, 47(3):187-200.

2. Carducci A, Tozzi E, Rubulotta E, Casini B, Cantiani L, Rovini E, Muscillo M, Pacini R: Assessing airborne biological hazard from urban wastewater treatment. Water Research 2000, 34(4):1173-1178.

3. Srikanth P, Sudharsanam S, Steinberg R: Bio-aerosols in indoor environment: composition, health effects and analysis. Indian J Med Microbiol 2008, 26(4):302-12.

4. Lindsley WG, Blachere FM, Thewlis RE, Vishnu A, Davis KA, Cao G, Palmer JE, Clark KE, Fisher MA, Khakoo R, Beezhold DH: Measurements of airborne influenza virus in aerosol particles from human coughs. PLoS One 2010, 5(11):e15100..

5. Hui DS, Chan PK: Severe acute respiratory syndrome and coronavirus. Infect Dis Clin North Am 2010, 24(3):619-638.

6. Hammond GW, Raddatz RL, Gelskey DE: Impact of atmospheric dispersion and transport of viral aerosols on the epidemiology of influenza. Rev Infect Dis 1989, 11(3):494-497.

7. Marks PJ, Vipond IB, Regan FM, Wedgwood K, Fey RE, Caul EO: A school outbreak of Norwalk-like virus: evidence for airborne transmission. Epidemiol Infect 2003, 131(1):727-736.

8. Verreault D, Moineau S, Duchaine C: Methods for sampling of airborne viruses. Microbiol Mol Biol Rev 2008, 72(3):413-444.

9. Yu IT, Li Y, Wong TW, Tam W, Chan AT, Lee JH, Leung DY, Ho T: Evidence of airborne transmission of the severe acute respiratory syndrome virus. N Engl J Med 2004, 350(17):1731-1739.

10. Yu IT, Wong TW, Chiu YL, Lee N, Li Y: Temporal-spatial analysis of severe acute respiratory syndrome among hospital inpatients. Clin Infect Dis 2005, 40(9):1237-1243.

11. Gibb AP, Wong S: Inhibition of PCR by agar from bacteriological transport media. J Clin Microbiol 1998, 36(1):275-276.

12. Moreira D: Efficient removal of PCR inhibitors using agarose-embedded DNA preparations. Nucleic Acids Res 1998, 26(13):3309-3310.

13. Hernroth BE, Conden-Hansson AC, Rehnstam-Holm AS, Girones R, Allard AK: Environmental factors influencing human viral pathogens and their potential indicator organisms in the blue mussel, Mytilus edulis: the first Scandinavian report. Appl Environ Microbiol 2002, 68(9):4523-4533.

14. Bofill-Mas S, Calgua B, Clemente-Casares P, La Rosa G, laconelli M, Muscillo M, Rutjes S, Husman AMD, Grunert A, Graber I, Verani M, Carducci A, Calvo M, Wyn-Jones P, Girones R: Quantification of human 
adenoviruses in European recreational waters. Food Environ Virol 2010, 2(2):101-109.

15. Kageyama T, Kojima S, Shinohara M, Uchida K, Fukushi S, Hoshino FB, Takeda N, Katayama K: Broadly reactive and highly sensitive assay for Norwalk-like viruses based on real-time quantitative reverse transcription-PCR. J Clin Microbiol 2003, 41(4):1548-1557.

16. Brandi G, Sisti M, Amagliani G: Evaluation of the environmental impact of microbial aerosols generated by wastewater treatment plants utilizing different aeration systems. J Appl Microbiol 2000, 88(5):845-852.

17. Fracchia L, Pietronave S, Rinaldi M, Giovanna Martinotti M: Site-related airborne biological hazard and seasonal variations in two wastewater treatment plants. Water Res 2006, 40(10):1985-1994.

doi:10.1186/1743-422X-8-369

Cite this article as: Ziros et al:: Development of an optimized method for the detection of airborne viruses with real-time PCR analysis.

Virology Journal 2011 8:369.

\section{Submit your next manuscript to BioMed Central} and take full advantage of:

- Convenient online submission

- Thorough peer review

- No space constraints or color figure charges

- Immediate publication on acceptance

- Inclusion in PubMed, CAS, Scopus and Google Scholar

- Research which is freely available for redistribution

Submit your manuscript at www.biomedcentral.com/submit 